\title{
PRODUCTION OF BIODEGRADABLE PLASTICS FROM SWEET POTATO SKINS WITH THE ADDITION OF CHITOSAN
}

\author{
Ismet $^{1}$, Chairul Amni ${ }^{1, ~} \bowtie$, Purwantiningsih ${ }^{2}$, Deden Saprudin ${ }^{2}$ and Ellysa ${ }^{3}$ \\ ${ }^{1}$ Department of Industrial Engineering, Engineering Faculty of Serambi Mekkah University, \\ Banda Aceh, Indonesia. \\ ${ }^{2}$ Department of Chemistry, IPB University, West Java, Indonesia. \\ ${ }^{3}$ Industrial Research and Standardization Center of Banda Aceh, Indonesia \\ ${ }^{\bowtie}$ Corresponding Author: chairul.amni@serambimekkah.ac.id
}

\begin{abstract}
Plastics are becoming more popular among the general public. Plastics are commonly used for packaging, which helps to keep products in good physical condition while also increasing their commercial value. The majority of plastic is made from materials that are difficult to decompose. A degradation process has a long phase. Over time, plastic waste has accumulated, causing air pollution in the surrounding areas. Plastic waste problems inspire many researchers to develop plastics that are more easily degraded and safe for the environment. This type of plastic is more commonly referred to as biodegradable plastic. The purpose of this study was to compare the composition of chitosan with the addition of glycerol as a plasticizer into sweet potato skins with starch concentrations of 1,3 , and 6 $\mathrm{mL}$. This study creates biodegradable plastic with thin, transparent, and versatile sheets as fine as a bright, faintly yellowish color. Tensile strength ranged from 2.3 to $4 \mathrm{~kg} \mathrm{f} / \mathrm{mm}^{2}$ and elongation from 2.1 to 4.8 percent. The density of biodegradable plastics ranged from 2.9 to 5.1 percent. SEM microstructure measurements revealed that the particles were tightly bound to each other, resulting in low absorbed water.
\end{abstract}

Keywords: Plastics, Packaging, Biodegradable, Sweet Potato.

RASĀYAN J. Chem., Vol. 14, No.4, 2021

\section{INTRODUCTION}

The issue of waste cannot be overlooked as a part of human life on this planet. It is being progressively increased, which can make something worse for environmental sustainability if it is not managed properly. ${ }^{1}$ The researchers explained that as much as $15 \%$ of the waste in Indonesia is plastic waste. So, it is shown that 220 million Indonesians create 26,500 tons of plastic waste each day. Plastics are nonbiodegradable packaging materials inferred from fuel synthesis. Its mechanical properties are great, the value is generally low, and the fabricating process and application are easy. ${ }^{2}$ Production synthetic plastic is the most popular packaging material in the community. However, synthetic plastics have a very high level of chemical physics stability, so plastics are tough to degrade by the environment. Various attempts have been made to deal with pollution problems caused by plastic waste, such as burning plastic, recycling, and stockpiling. Large amounts of plastic combustion can produce corrosive and harmful gases such as $\mathrm{HCl}, \mathrm{HCN}, \mathrm{NH}_{3}$, and $\mathrm{SO}_{2} \cdot{ }^{3,4}$ Furthermore, when the polyolefin group's plastic material is burned, it does not degrade but rather melts and then solidifies at room temperature. ${ }^{5}$ The recycling procedure is expensive and inefficient because it must be divided into plastic waste that can be recycled and waste that cannot be recycled. Because plastic resources normally have an obstacle high enough for $\mathrm{O}_{2}$ and $\mathrm{CO}_{2}$ permeability, removing plastic waste from landfills significantly disrupts air circulation to and from the soil. $^{6}$

Numerous alternatives have been developed by researchers and the general public to substitute for environmentally friendly resources, namely plant resources. ${ }^{7-9}$ As a result, a few farming products, such as potatoes, corn, soybeans, sago, and sweet potato skin, have been identified as having the potential to use adaptable biopolymers. The sweet potato is a tropical tuber that is edible and has pinkish-orange, slightly sweet flesh. It is a type of fruit that grows in dense forests but is underutilized because it contains

Rasayan J. Chem., 14(4), 2749-2753(2021)

http://dx.doi.org/10.31788/RJC.2021.1446363

This work is licensed under a CC BY 4.0 license. 
poisons and is easily discarded. While sweet potato skin contains starch that can be used, one of its uses as a raw material for producing biodegradable plastics is likely to reduce environmental pollution while increasing the potential of sweet potato peels, which have previously been considered less economical. However, in order to make biodegradable plastic that is more effective and has mechanical properties (especially due to its versatility), sweet potato skin starch must be blended through plasticizing. Glycerol is being used as a plasticizer in research. ${ }^{10}$

\section{Preparation of Sweet Potato Skins Starch}

\section{EXPERIMENTAL}

Five grams of sweet potato skin were dissolved in $100 \mathrm{ml}$ of distilled water in a beaker glass and mixed for 25 minutes. ${ }^{10}$ Chitosan concentrations of up to $1 \%, 3 \%$, and $9 \%$ are mixed with diluted glacial acetic acid. When the mixture is uniform, a starch solution in a specific ratio is added to a beaker placed on a hot plate. Using a hot plate is to accelerates the reaction by raising the temperature. Then, put the magnetic stirrer in a glass. The purpose of using a magnetic stirrer is to prevent the formation of clots within the starch while heating and to aid in straightening heat spread. The purpose of using a hot plate is to accelerate the reaction by raising the temperature. Then, put the magnetic stirrer in a glass. The purpose of using a magnetic stirrer is to prevent the formation of clots within the starch while heating and to aid in straightening heat spread. Starch is heated to $80{ }^{\circ} \mathrm{C}$ and then used for 15-20 minutes. ${ }^{11}$

\section{Production of Biodegradable Plastics}

$1 \mathrm{~mL}, 3 \mathrm{~mL}$, and $6 \mathrm{~mL}$ of plasticizer (glycerol) were added to sweet potato skin starch. The goal of including glycerol is to provide versatile properties. While adding glycerol, the starch must be constantly blended for 15 minutes to prevent lumps and speed up the homogenization of the starch-glycerol blend. The glass is then removed from the hot plate. After removing the starch mixture, it must be stirred for 30 minutes while the temperature remains between $25{ }^{\circ} \mathrm{C}$ and $30{ }^{\circ} \mathrm{C}$ to ensure that the viscosity remains constant. Following the formation of the starch mixture, the temperature of the starch mixture is normal. In that case, the mixture is poured onto the glass with a width of about $1 \mathrm{~mm}$, which has been designated as "duct ribbon" on the boundaries. The goal of using duct tape is to keep the starch mixture from spilling past the glass's border. Pouring the starch mixture must be done slowly. A thin layer formed on the glass is solidified and dried for 4 hours in a $70{ }^{\circ} \mathrm{C}$ oven. The dehydrated, thin layer is separated from the glass by gradually opening it with the help of a razor-sharp edge, allowing it to escape the glass casting. The plastic is transferred to the desiccator and stored in a non-sunlit location for one day. ${ }^{11-13} \mathrm{~A}$ scanning electron microscope (SEM) was used to examine the samples for tensile strength, elongation, and density. The mechanical properties of the sample are defined by its tensile strength, which will be determined using Computer Type Universal Testing Machines HT-8503. The tensile strength sample is cut following the ASTM-D638 standard.

\section{Mechanical Properties}

\section{RESULTS AND DISCUSSION}

The results of tensile strength with elongation are shown in Fig-1. The graph appearance of adding Chitosan to the glycerol concentration is affected by the tensile strength of biodegradable plastics. This study is also in line with research conducted by ${ }^{10}$ which states that the tensile strength of biodegradable plastics increased with the increase of starch: glycerol ratio. Furthermore, the ratio of added chitosan to tensile strength values is a straight line, as shown in Fig.-1. As the chitosan content increases, so does the tensile strength. A biodegradable plastic with a chitosan content of 6 grams has a higher tensile strength than biodegradable plastics with a chitosan content of $3 \%$, and so on. The higher the chitosan content, the more hydrogen bonds will be encased in biodegradable polymers, explaining this potency. ${ }^{14}$

Elongation testing was performed to determine the length of a polymer before it broke up. The measurement of elongation of break is performed concurrently with the measurement of tensile strength. The extension break test results are shown in Fig.-2.

As shown in Fig-2, the percentage of elongation is inversely proportional to the concentration of chitosan,. The percentage of elongation decreases as the chitosan concentration increases. The highest elongation percentage was obtained with a 1 percent chitosan to $6 \mathrm{~mL}$ glycerol mixture ratio. This 
RASĀYAN $J$. Chem.

Vol. 14 | No. 4 |2749-2753| October- December | 2021

elongation is caused by a decrease in the distance between intermolecular bonds as a result of the high amount of glycerol used as a plasticizer. ${ }^{13}$

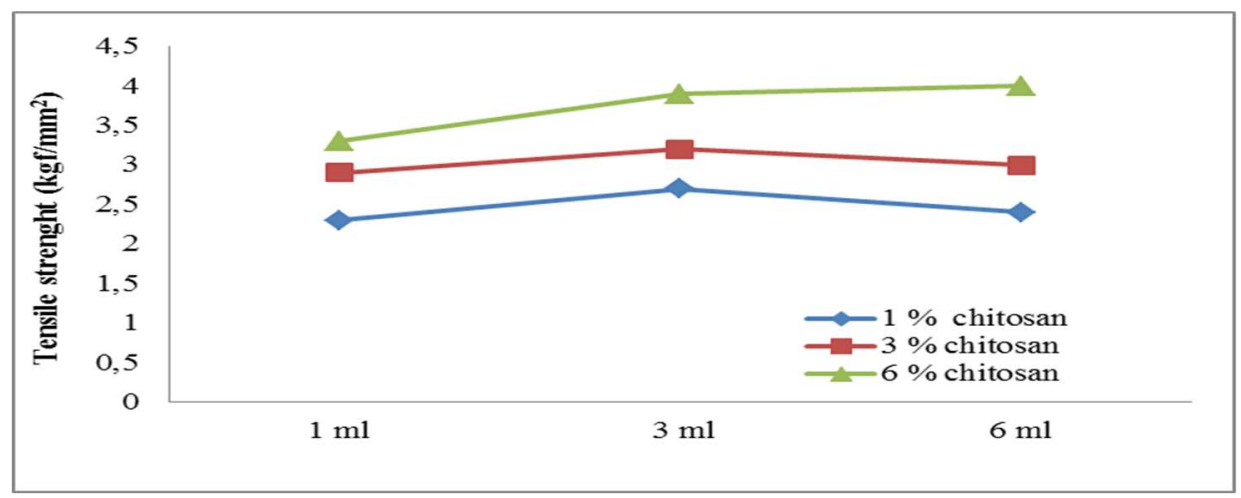

Fig.-1: The Effect of Chitosan Addition Ratio on Tensile Strength Values with Various Volumes of Glycerol

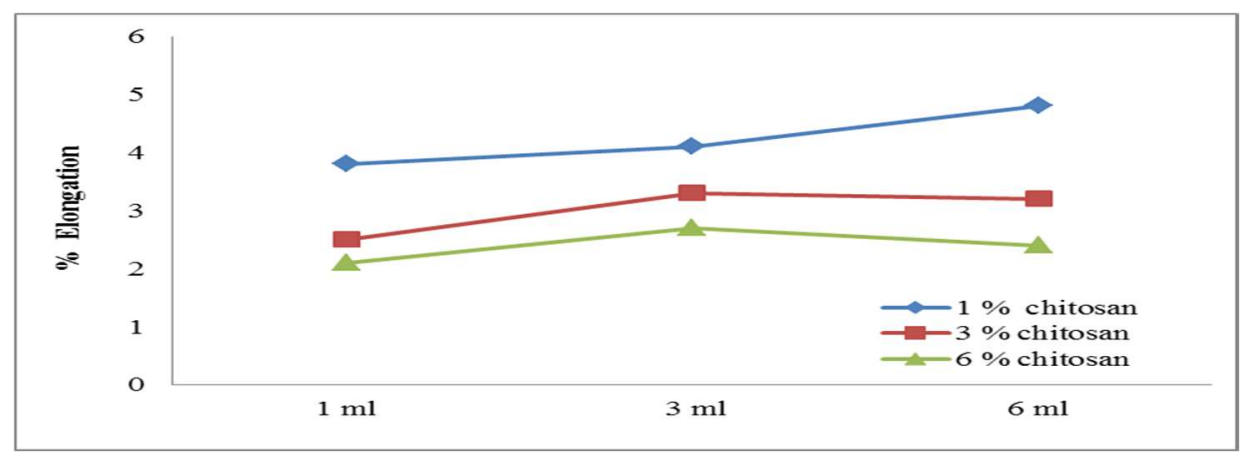

Fig.-2: The Effect of Chitosan Concentration Ratio on Elongation

\section{The Density Measurement}

Density is a measurement of material mass per unit volume $(\mathrm{gr} / \mathrm{ml})$. The purpose of this test is to determine the density of biodegradable plastic. Bioplastic density testing is performed by weighing a $3 \mathrm{x}$ $1 \mathrm{~cm}$ sample and then inserting it into a measuring cup filled with water to determine its volume value. The volume is calculated by comparing the water level before and after entering the water. Figure-3 depicts the relationship between the density of biodegradable plastics and the addition of chitosan and glycerol.

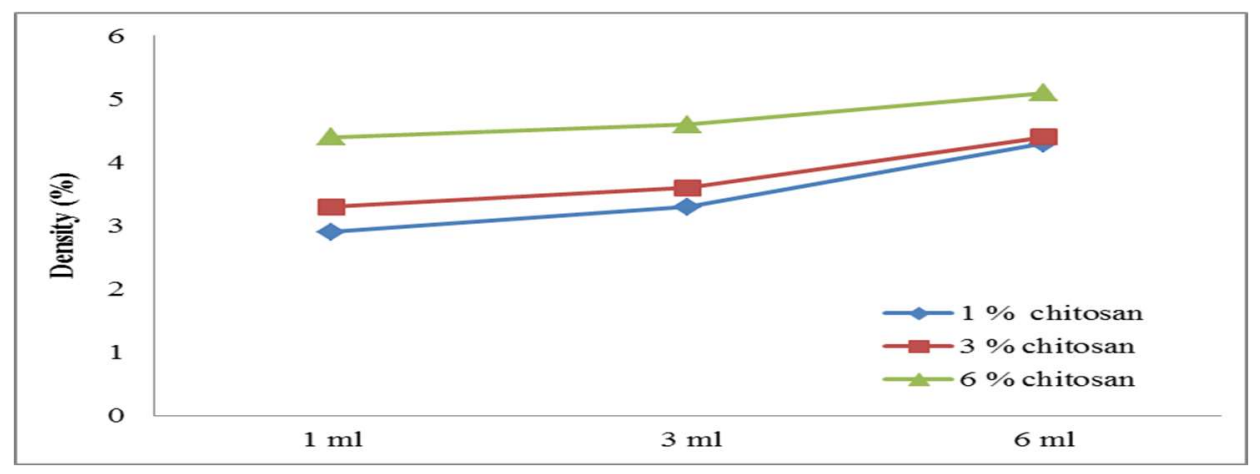

Fig.-3: Effect of Chitosan Concentration Ratio to Density

According to Fig.-3, the more chitosan added, the higher the value of the density of biodegradable plastic. Similarly, as the amount of glycerol added increases, so does the value of the density of biodegradable plastic. ${ }^{15}$ At a 6 percent ratio, chitosan with $6 \mathrm{~mL}$ glycerol obtained the highest density, with 5.1 percent, and the smallest density was obtained with 2.9 percent in a mixture of 1 percent chitosan and $1 \mathrm{~mL}$ 
RASĀYAN J. Chem.

Vol. 14 | No. 4 |2749-2753| October- December | 2021

glycerol. The more chitosan and glycerol are added, the more biodegradable plastics are produced. Density is directly proportional to mass, so the greater the mass of a material, the greater the density value. $^{11}$

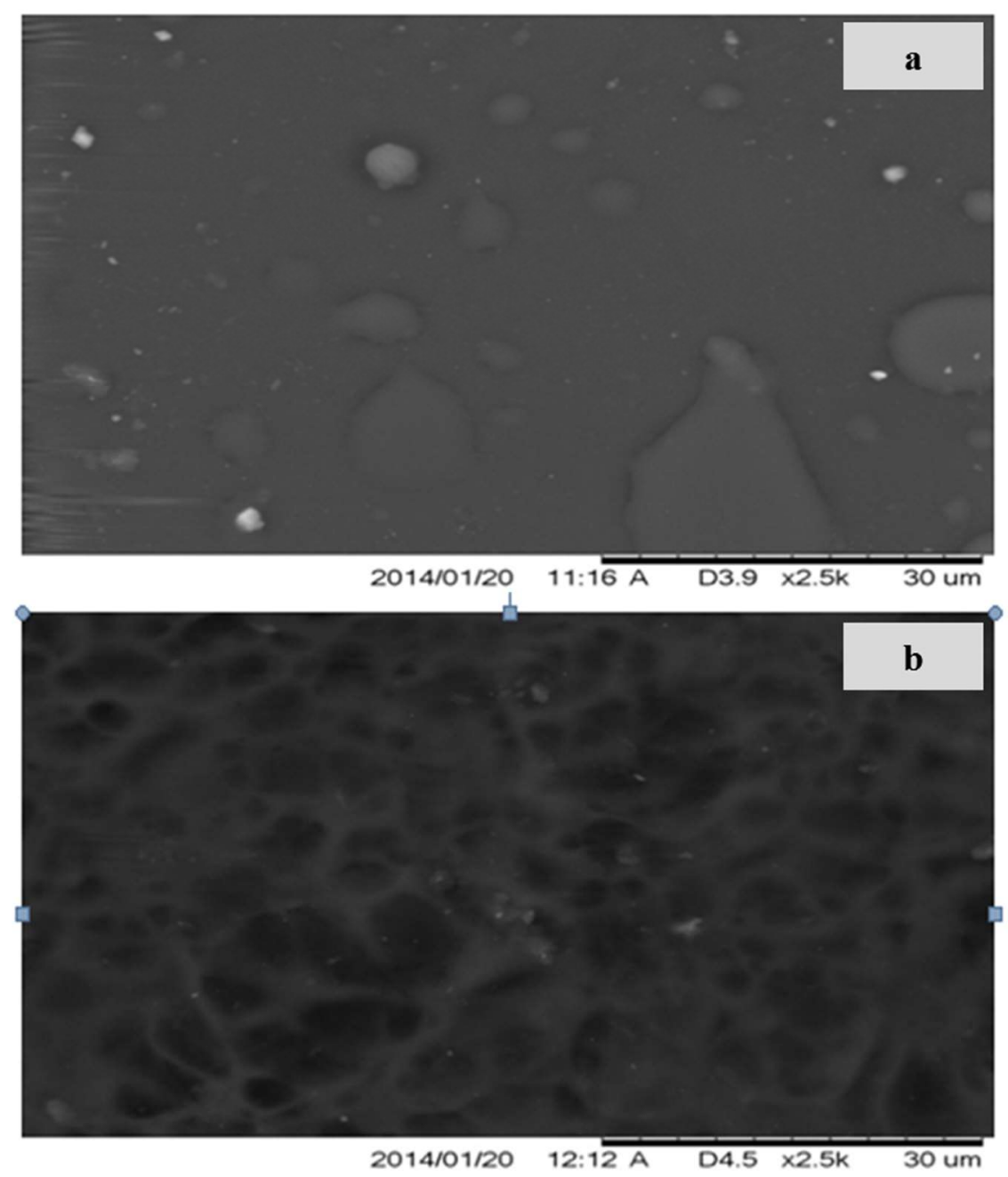

Fig.-4: SEM of Biodegradable Plastics in (a) Surface and (b) Cross-section at a Ratio of $6 \%$ Chitosan to $6 \mathrm{ml}$ of

\section{Morphology Test}

Glycerol

Morphological analysis with SEM aims to determine biodegradable plastics' homogeneity, surface structure, cracks, and surface smoothness of alloyed products. Figure- 4 shows the results of the SEM analysis at 2500x magnification. The figure above depicts microstructure observation using SEM for biodegradable plastics samples. The particles appear to bind to each other and are quite tight, so that the absorbed water is quite low compared to other biodegradable plastics. However, there are uneven pores caused by insufficient stirring. The resulting morphological structure of the film is not homogeneous due to insufficient mixing and the presence of chitosan, which is insoluble in organic solvents. ${ }^{10}$

There are air bubbles on the surface of the resulting biodegradable plastic. Stirring and biodegradable plastics printing processes cause air cavities, which affect the surface structure of the biodegradable plastics produced. The better the printing process, the faster the water vapor in the material evaporates, causing the particles of the material to move upwards and cause the inter-cell layer to fuse. The presence of pores is visible in the sample cross-sectional structure shown in Fig.-4 (b). Because starch-based films have a low moisture and gas transmission rate, they have small pores. The figure also shows that even though the starch granules are not intact, they still have a structure. The largest granule can still be seen a diameter of $30 \times 10^{-6} \mathrm{~m}$. The granular diameter of starch derived from plant seeds, tubers, roots, and stems ranges between 2 and $100 \times 10^{-6} \mathrm{~m}$. 


\section{CONCLUSION}

The production of biodegradable plastic from sweet potato skins with Chitosan has been completed successfully. The greater the amount of glycerol added to biodegradable plastic materials, the lower the tensile strength value and the greater the elongation value. The density analysis shows an increase with the addition of chitosan concentration.

\section{ACKNOWLEDGMENT}

The Ministry of Research, Technology, and Higher Education of Indonesia supported this research through the PKPT scheme with Serambi Mekkah University.

\section{REFERENCES}

1. L. K. Ncube, A. U. Ude, E. N. Ogunmuyiwa, R. Zulkifli, and I. N. Beas, Recycling, 6, 12(2021), https://doi.org/10.3390/recycling6010012

2. Y. A. Hidayat, S. Kiranamahsa, and M. A. Zamal, AIMS Energy, 7, 3(2019), https://doi.org/10.3934/energy.2019.3.350

3. V. M. Pathak, Bioresources and Bioprocessing., 4, 15(2017), https://doi.org/10.1186/s40643-0170145-9

4. A. Folino, A. Karageorgiou, and P. S. Calabr, Sustainability, 12, 6030(2020), https://doi.org/10.3390/su12156030

5. L. W. McKeen, plastics design library (pdl) handbook series, (2019), https://doi.org/10.1016/B978-012-816457-0.00008-3

6. A. Melani, D. Putri, and Robiah, Distilasi, 4, 2(2019), https://doi.org/10.32502/jd.v4i2.2208

7. Y. Widodo, S. Wahyuningsih, and A. Ueda, Procedia Chemistry, 14, (2015), https://doi.org/10.1016/j.proche.2015.03.066

8. U. Ulyarti, L. Lavlinesia, S. Surhaini, N. Siregar, A. Tomara, L. Lisani, and N. Nazarudin, Makara Journal of Science, 25, 2(2021), https://doi.org/10.7454/mss.v25i2.1155

9. P. A. Owusu and S. Asumadu-sarkodie, Cogent Engineering, 3, 1167990(2016), https://doi.org/10.1080/23311916.2016.1167990

10. A. H. Dawam Abdu, S. Pudjirahar, M. Karina, O. Dwi Putri, and R. H. Fauziyyah, Journal of Biological Sciences, 19, 1(2018), https://doi.org/10.3923/jbs.2019.57.64

11. C. Amni, Ismet, S. Aprilia, and Mariana, International Journal of Engineering \& Technology., 7, 4(2018), https://doi.org/10.14419/ijet.v7i4.23127

12. C. Amni, Ismet, S. Aprilia, and Mariana, IOP Conf. Series: Earth and Environmental Science, $\mathbf{3 6 5}$, 1(2019), https://doi.org/10.1088/1755-1315/365/1/012052

13. C. Amni, M. Marwan, and M. Mariana, Jurnal Litbang Industri, 5, 2(2015), https://doi.org/10.24960/jli.v5i2.670.91-99

14. V. Zargar, M. Asghari, and A. Dashti, ChemBioEng Reviews, 2, 3(2015), https://doi.org/10.1002/cben.201400025

15. I. Nafiayanto, Integrated Lab Journal, 07, 01(2019), https://doi.org/10.5281/zenodo.2656812

[RJC-6363/2021] 